\title{
Note
}

\section{Quantitative high-performance liquid chromatography of structurally similar nucleosides}

WILLIAM SCHROEDER, III, THOMAS L. CUPPS and LEROY B. TOWNSEND*

Department of Medicinal .Chemistry, College of Pharmacy and Department of Chemistry, University of Michigan, Ann Arbor, MI 48109 (U.S.A.)

(First received April 27th, 1982; revised manuscript received September 14th, 1982)

When any biological or chemotherapeutic activity is observed for a compound derived from a chemotherapeutic or biologically active starting material, the investigator must be certain that this compound is pure and not contaminated by even a small amount of starting material. If, for example, a compound $\mathrm{X}$ has demonstrated significant cytotoxicity in cell culture tests at a concentration of $10^{-9} \mathrm{M}$, then it is reasonable to assume that $0.1 \%$ of compound $\mathrm{X}$ in a product $\mathrm{Y}$, which was obtained by a chemical modification of compound $\mathrm{X}$, should exhibit cytotoxicity at a concentration of $10^{-6} M$. In many test systems, activity at this concentration is sufficient to warrant additional testing. The routine detection of a $0.1 \%$ contamination of starting material can, in some instances, be a difficult task. The problem is especially complicated with structurally similar compounds for which traditional methods such as elemental analysis and thin-layer chromatography may fail to detect the contamination. Therefore, it is imperative that the analytical method selected to test for product purity be sensitive enough to detect such a small but significant impurity.

As we have been involved in the structural modification ${ }^{1-3}$ of chemotherapeutically active nucleosides, it was obvious that we needed an analytical method which would establish unequivocally that our products did not contain inordinate amounts of impurities. Therefore, we elected to investigate the use of high-performance liquid chromatography (HPLC) as both a qualitative and a quantitative analytical tool. Ion-exchange HPLC has been used in the separation of nucleosides and bases ${ }^{4,5}$ and nucleotides ${ }^{6}$; however, more recent investigations have shown that reversedphase HPLC of nucleosides ${ }^{7-9}$ offers simplicity ${ }^{10}$ and efficiency in the resolution of complex mixtures of nucleosides and bases ${ }^{11}$. We report here that the application of reversed-phase HPLC has allowed us to develop a sensitive method that is convenient for the detection and quantitation of small amounts of structurally similar nucleosides. To demonstrate the utility and convenience of this method, we elected to use the nucleosides adenoside (Ado), adenine arabinoside (Ara-A) and 2'-deoxyadenosine ( $\left.2^{\prime} \mathrm{d}-\mathrm{A}\right)$ and various mixtures thereof. Inosine (Ino) was arbitrarily selected as the internal standard. These four compounds are commercially available and possess structural similarities that are typical of those which might be encountered in a series possessing similar biological and/or chemotherapeutic activity. 

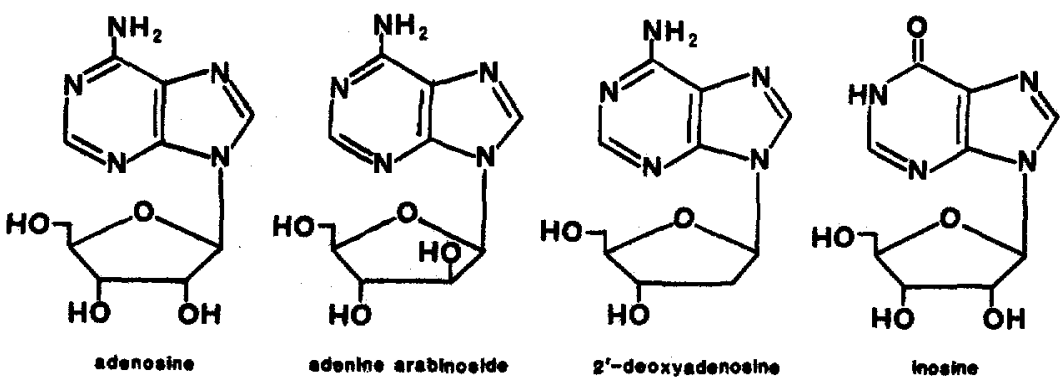

\section{EXPERIMENTAL}

\section{Apparatus}

All studies were conducted with a Varian Model 5040 chromatograph coupled with a Varian Vista 401 data station and a Varian UV-50 variable-wavelength detector. The injection valve was a Rheodyne Model 7125 with a $10-\mu l$ fixed-volume sample loop. A Whatman Partisil 10/ODS-3 reversed-phase column $(250 \times 4.6 \mathrm{~mm}$ I.D.) was used, preceded by a Brownlee C-18 guard cartridge system.

\section{Chemicals}

Adenosine, adenine-arabinoside, 2 -deoxyadenosine and inosine were obtained from commercial sources.

\section{Reagents}

Ultrex-grade potassium dihydrogen phosphate and reagent-grade glacial acetic acid were purchased from J. T. Baker (Phillipsburg, NJ, U.S.A.). Dimethyl sulfoxide (DMSO) was purchased from Fisher Scientific (Pittsburgh, PA, U.S.A.) and acetonitrile (UV grade, distilled in glass) from Burdick \& Jackson Labs. (Muskegon, MI, U.S.A.). Water was first distilled and then further purified with a Millipore Milli-Q purification system.

\section{Buffer}

The elution buffer was prepared on a daily basis. Potassium dihydrogen phosphate $(1.361 \mathrm{~g}, 0.010$ mole) was dissolved in purified water $(1000 \mathrm{ml})$ and, after stirring for approximately $10 \mathrm{~min}$, the solution was titrated potentiometrically with acetic acid to $\mathrm{pH} 3.250 \pm 0.005$.

\section{Stock nucleoside solutions}

Four single-compound stock solutions were prepared by adding each of the nucleosides to a small amount of warm HPLC water in separate $100-\mathrm{ml}$ volumetric flasks. After DMSO $(1.0 \mathrm{ml})$ had been added to each of the four solutions, in order to facilitate solubility, each solution was then diluted to the $100-\mathrm{ml}$ mark with HPLC water (at $25^{\circ} \mathrm{C}$ ). The concentrations of each of these solutions are listed in Table I.

\section{Calibration standard}

A calibration standard solution containing each of the three nucleosides ad- 
TABLE I

COMPOSITIONS OF $100 \mathrm{ml}$ OF STOCK NUCLEOSIDE SOLUTION

\begin{tabular}{lll} 
Nucleoside & $\begin{array}{l}\text { Wt. of nucleoside } \\
( \pm 0.7 \mathrm{mg})^{12}\end{array}$ & $\begin{array}{l}\text { Concentration of } \\
\text { solution }(\mathrm{mg} / \mathrm{ml})\end{array}$ \\
\hline Adenosine & 100.2 & $1.00 \pm 0.01$ \\
Adenine arabinoside & 100.2 & $1.00 \pm 0.01$ \\
2'-Deoxyadenosine & 100.8 & $1.01 \pm 0.01$ \\
Inosine & 10.1 & $0.101 \pm 0.001$ \\
\hline
\end{tabular}

enosine, adenine arabinoside and 2 -deoxyadenosine was accurately prepared by combining aliquots $(125 \pm 3 \mu \mathrm{l})$ from each of the three stock solutions in a $25.0-\mathrm{ml}$ volumetric flask. An aliquot $(1250 \pm 10 \mu \mathrm{l})$ of inosine stock solution was added to the flask and then the solution was diluted to $25.0 \mathrm{ml}$ with HPLC water at $25^{\circ} \mathrm{C}$. This furnished a solution containing accurate concentrations of each of the four nucleosides $\left(5.00 \pm 0.02 \mu \mathrm{g} / \mathrm{ml}\right.$ each of Ado, Ara-A, ${ }^{\prime} \mathrm{d}-\mathrm{A}$ and $5.05 \pm 0.02 \mu \mathrm{g} / \mathrm{ml}$ of Ino). The chromatogram for this calibration standard is presented in Fig. 1.

\section{Solutions of nucleoside mixtures}

Six two-component solutions were prepared, each containing a major component nucleoside and a trace impurity component of a second nucleoside. In addition, each solution also contained the internal standard iosine $(5.0 \mu \mathrm{g} / \mathrm{ml})$.

These solutions were prepared by pipeting specific aliquots from the four stock solutions into a $25-\mathrm{ml}$ volumetric flask and diluting to $25.0 \mathrm{ml}$ with purified water at $25^{\circ} \mathrm{C}$. They are listed together with their component concentrations in Table II.

Representative chromatograms for mixtures 1, 2, 3, 4 and 6 (Table III) are shown in Fig. 2.

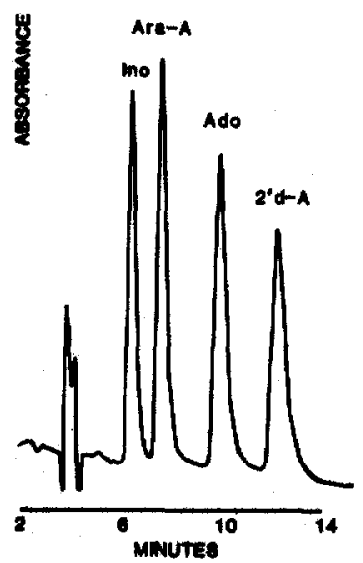

Fig. 1. Reversed-phase separation of the calibration standard solution on a Whatman Partisil 10/ODS-3 column $(250 \times 4.6 \mathrm{~mm})$ with acetonitrile-working buffer $(5: 95)$ as eluent. Flow-rate, $1.0 \mathrm{ml} / \mathrm{min}$; detection at $254 \mathrm{~nm}$. 

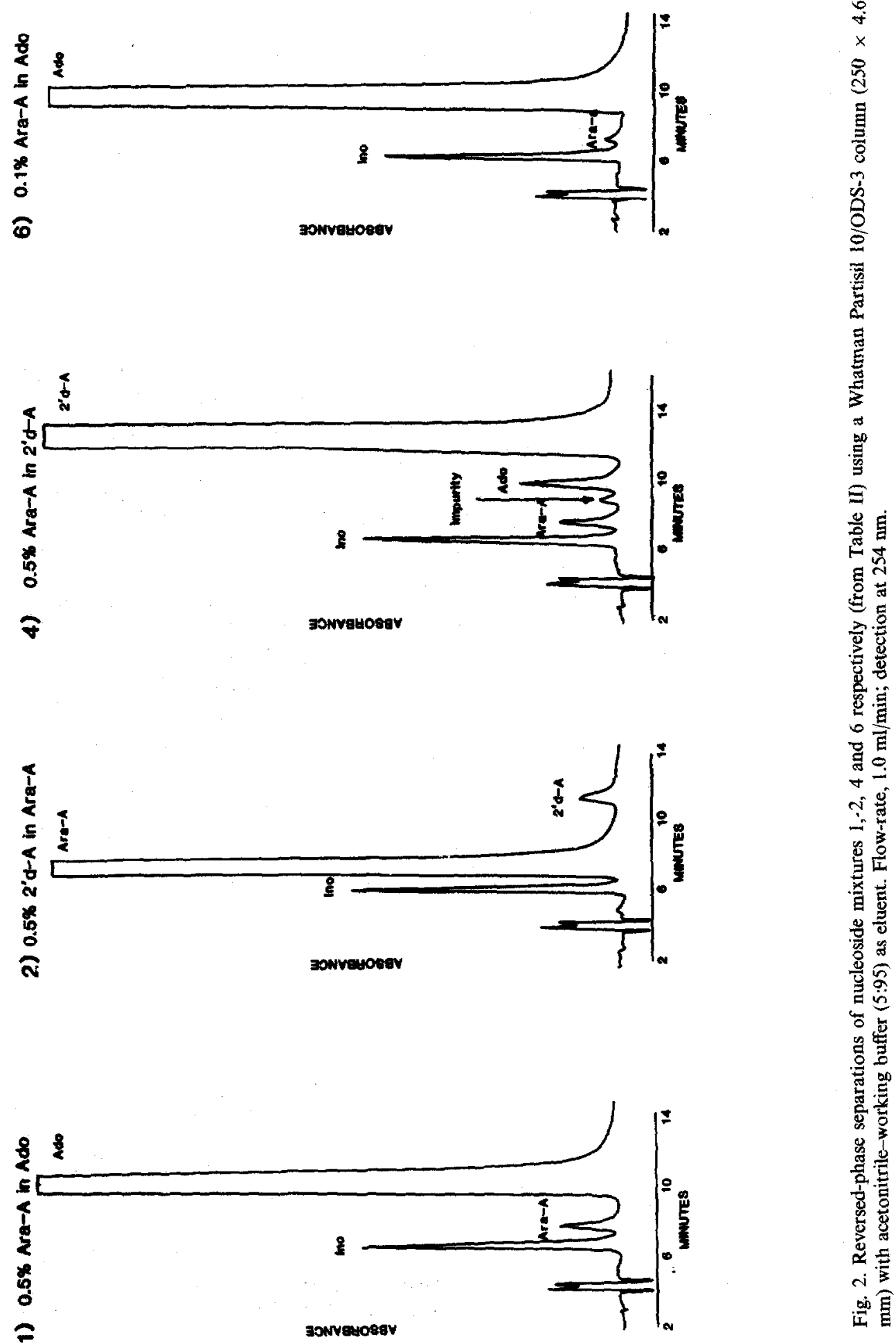


\section{TABLE II}

\section{COMPOSITIONS OF SOLUTIONS OF NUCLEOSIDE MIXTURES}

Solutions ( $25 \mathrm{ml}$ ) of nucleoside mixtures each containing a major component, an impurity component and the internal standard inosine $(5.05 \mu \mathrm{g} / \mathrm{ml})$.

\begin{tabular}{|c|c|c|c|c|c|}
\hline \multirow[t]{2}{*}{ Mixture No. } & \multicolumn{2}{|l|}{$\begin{array}{l}\text { Major } \\
\text { component }\end{array}$} & \multicolumn{3}{|c|}{ Impurity component } \\
\hline & Nucleoside & $\begin{array}{l}\text { Concentration } \\
(\mu \mathrm{g} / \mathrm{ml}) \\
\left( \pm 5 \mu \mathrm{g} / \mathrm{ml}^{\star}\right)\end{array}$ & Nucleoside & $\begin{array}{l}\text { Concentration } \\
(\mu \mathrm{g} / \mathrm{ml}) \\
\left( \pm 0.02 \mu \mathrm{g} / \mathrm{m}^{\star}\right)\end{array}$ & $\begin{array}{l}\text { Concentration of } \\
\text { major componen } \\
(\%)( \pm 0.02 \%)\end{array}$ \\
\hline 1 & Ado & 200 & Ara-A & 1.00 & 0.50 \\
\hline 2 & Ara-A & 200 & $2^{\prime} \mathrm{d}-\mathrm{A}$ & 1.01 & 0.50 \\
\hline 3 & $2 \prime d-A$ & 200 & Ado & 1.00 & 0.50 \\
\hline 4 & $2 ' d-A$ & 200 & Ara-A & 1.00 & 0.50 \\
\hline 5 & Ado & 200 & Ara-A & 0.50 & 0.25 \\
\hline 6 & Ado & 200 & Ara-A & 0.20 & 0.10 \\
\hline
\end{tabular}

* Experimental error was calculated for each solution using the following formula:

$$
d=\left[\left(\frac{\alpha}{x}\right)^{2}+\left(\frac{\beta}{y}\right)^{2}\right]^{1 / 2}\left(\frac{x}{y}\right)
$$

where $d$ is the error in the term $x / y, \alpha$ is the error in $x$ and $\beta$ is the error in $y$.

\section{RESULTS AND DISCUSSION}

In order to demonstrate the reproducibility and detection limits of this quantitative HPLC method, we made three non-consecutive injections of each of the six nucleoside mixtures described in Table II for a total of 18 injections. Table III lists the data for each of these injections together with calculated averages and standard deviations (S.D.). It should be noted that the measured concentration values were

\section{TABLE III}

\section{CONCENTRATIONS OF NUCLEOSIDE MIXTURES MEASURED BY HPLC}

\begin{tabular}{|c|c|c|c|c|c|c|}
\hline \multirow[t]{2}{*}{ No. } & \multirow{2}{*}{$\begin{array}{l}\text { Nucleoside mixture } \\
( \pm 0.02 \%)\end{array}$} & \multicolumn{5}{|c|}{ Measured concentration (\%) } \\
\hline & & Run 1 & Run 2 & Run 3 & Average & $\begin{array}{l}\text { Standard } \\
\text { deviation }\end{array}$ \\
\hline 1 & $0.50 \%$ Ara-A in Ado & 0.53 & 0.48 & 0.54 & 0.52 & 0.03 \\
\hline 2 & $0.50 \% 2 \mathrm{~d}-\mathrm{A}$ in Ara-A & 0.51 & 0.44 & 0.44 & 0.46 & 0.04 \\
\hline 3 & $0.50 \%$ Ado in $2 \%-\mathrm{A}^{*}$ & $0.50 \star \star$ & $0.55 \star \star$ & $0.47 \star \star$ & 0.51 & 0.04 \\
\hline 4 & $0.50 \%$ Ara $-A$ in $2 \%-A^{\star}$ & 0.50 & 0.51 & 0.58 & 0.53 & 0.04 \\
\hline 5 & $0.25 \%$ Ara-A in Ado & 0.26 & 0.24 & 0.24 & 0.25 & 0.01 \\
\hline 6 & $0.10 \%$ Ara- $A$ in Ado & 0.09 & 0.07 & 0.08 & 0.08 & 0.01 \\
\hline
\end{tabular}

* The 2 'd-A sample was found to contain $1.1 \%$ of Ado as a contaminant.

* Values for the concentration of Ado have been corrected to take account of the $1.1 \%$ of Ado contamination present in the 2 'd-A sample. 
generated by the internal standard method of quantitation ${ }^{13}$, which we feel is preferable to other methods of quantitation (such as the external standard method) because it requires infrequent calibration and indirectly helps to minimize errors due to the relative insolubility of the nucleosides in water. Examination of the data in Table III shows the measured concentration values for mixtures $1-4$ to be generally within experimental error.

The standard deviation value (S.D.) was included to give an indication of the quantitative detection limit for the system. When the concentration of impurity was $0.25 \%$ or greater, the measured concentration closely matched the actual concentration in the analytical solutions. However, when the impurity level was reduced to $0.10 \%$ (mixture 6 , Table III), the measured values deviated severely from the known concentration. Therefore, we consider the minimum concentration of impurity required for reproducible quantitation to be approximately $0.25 \%(19$ pmole, calculated as adenosine). However, simple detection can obviously be achieved with less than $0.10 \%$ impurity ( $<8 \mathrm{pmol}$ ) and this level of detection agrees very well with previously published work ${ }^{7,12}$. It was discovered that two samples of $2^{\prime}$-deoxyadenosine (ohtained from different commercial sources) contained moderate amounts of adenosine $(1.1-1.7 \%$. These samples also contained an unknown impurity eluting at about 8.3 min. Assuming that the UV absorption of this impurity is similar to that of adenosine, the relative concentration of this compound is approximately $0.2 \%$. This impurity was observed in the chromatogram (Fig. 2) obtained on the $0.50 \% 2$ d-A in Ara- $\Lambda$ mixture (No. 4, Table III). While this did not cause any difficulty with our analyses, it does further exemplify the usefulness of this HPLC method and is illustrated in Fig. 2.

\section{CONCLUSIONS}

We have developed a method involving aqueous reversed-phase HPLC which has readily separated and quantitated mixtures of the structurally similar nucleosides adenosine, adenine arabinoside and 2'-deoxyadenosine. We have demonstrated that reproducibility can be achieved at an impurity concentration of $0.25 \%$ and that impurities can be detected at concentrations less than $0.10 \%$. We feel that this is a simple and sensitive method for detecting trace amounts of biologically active nucleoside material in nucleoside preparations and that it can have more general applications in other areas of synthesis which may involve chemical manipulations of biologically active material.

\section{ACKNOWLEDGEMENT}

This investigation was supported by grant number CA-28381 awarded by the National Cancer Institute, DHEW, and NIH training grant No. 5-T-32-GM07767. We also thank Ms. L. Pearson for her help with the preparation of the manuscript.

\section{REFERENCES}

I A. F. Lewis and L. B. Townsend, J. Amer. C'hem. Soc., 102 (1980) 2817.

2 G. A. Bhat, J. B. Montero, R. P. Panzica, L. L. Wotring and L. B. Townsend, J. Med. Chem., 24 (1981) 1165 . 
3 A. F. Lewis and L. B. Townsend, I. Amer. Chem. Soc., 104 (1982) 1073.

4 R. A. Hartwick, S. P. Assenza and P. R. Brown, J. Chromatogr., 186 (1979) 647, and references cited therein.

5 E. Nissiner, Anal. Biochem., 106 (1980) 497.

6 J. X. Khym, J. Chromatogr., 97 (1974) 277.

7 C. W. Gehrke, K. C. Kuo, G. E. Davis, R. D. Suits, T. P. Waalkes and E. Borek, J. Chromatogr., 150 (1978) 455.

8 Y. M. Rustum, Anal. Biochem., 90 (1978) 289.

9 R. A. Hartwick and P. R. Brown, J. Chromatogr, 126 (1976) 679.

10 C. W. Gehrke, K. C. Kuo and R. W. Zumwalt, J. Chromatogr., 188 (1980) 129.

11 M. Zakaria and P. R. Brown, J. Chromatogr., 226 (1981) 267.

12 K. C. Kuo, R. W. Zumwalt, P. F. Agris, and C. W. Gehrke, J. Chromatogr, submitted for publication.

13 L. R. Snyder and J. J. Kirkland, Introduction to Modern Liquid Chromatography, Wiley, New. York, 2nd ed., 1979 , p. 552 . 